\title{
Estimation of genetic parameters for cow age at last calving under different censorship criteria
}

\author{
S.B. Ramos ${ }^{\mathrm{a}}$, S.L. Caetano ${ }^{\mathrm{b}}$, G.J.M. Rosa ${ }^{\mathrm{c}}$, R.P. Savegnago ${ }^{\mathrm{d}}$, E.L. Kern ${ }^{\mathrm{d}}$, P.A. Bernardes ${ }^{\mathrm{d}}$, \\ R.B. Lôbo ${ }^{\mathrm{e}}$, D.P. Munari ${ }^{\mathrm{d}, *}$ \\ a Universidade de Franca (UNIFRAN), 14404-600 Franca, SP, Brazil \\ b Centro Universitário da Fundação Educacional de Barretos, 14783-226 Barretos, SP, Brazil \\ ${ }^{\mathrm{c}}$ Department of Animal Science, University of Wisconsin, 53706 Madison, WI, USA \\ d Departamento de Ciências Exatas, Faculdade de Ciências Agrárias e Veterinárias (FCAV), Universidade Estadual Paulista (UNESP), 14884-900 Jaboticabal, SP, Brazil \\ e Associação Nacional dos Criadores e Pesquisadores (ANCP), 14020-230 Ribeirão Preto, SP, Brazil
}

\section{A R T I C L E I N F O}

\section{Keywords:}

Heritability

Longevity

Weibull model

Survival analysis

\begin{abstract}
A B S T R A C T
Cow longevity measured by age at last calving was evaluated using a censorship criterion that consisted of the difference between the dates of age at last calving and the last calving on the farm. If this difference was greater than certain value, the cow failed, indicating that it should be discarded. Otherwise, the cow was censored indicating the possibility of future calving. The aim of this study was to estimate heritability and breeding values of bulls for longevity considering three different censorship criteria, 16, 26 and 36 months, using Weibull proportional hazard sire model. The 16-month criterion was proposed because it is the estimated average interval between births in Nellore. The 26-month criterion was proposed because it is an average value between 16 and 36 months. Lastly, the 36-month criterion was considered a long time interval for the cow have a new calving. The Spearman correlation test was used to compare the rankings of the bulls regarding the estimates of breeding values for longevity considering the different censorship criteria. The records of 21996 Nellore cows were used. The cows were the daughters of 2113 bulls from 13 farms that participate in the Nellore breeding program of the National Association of Breeders and Researchers (ANCP). Age at first calving was considered a fixed effect while the random effect was the contemporary group (season, year of birth, and herd) and sire. Heritability estimates for cow age at last calving were $0.1020,0.1002$ and 0.0871 for the 16, 26 and 36-month censorship criteria, respectively. The Spearman correlation estimates of sires' rankings were $-0.2124,0.1348$ and 0.1211 ( $\mathrm{P}>0.05$ ) for the censorship criteria of 16-26 months, 16-36 months, and 26 and 36 months, respectively. Despite of the little genetic variance to age at last calving, this values were higher than those reported in the literature. The accuracy of the selected bulls varies depending on the criteria adopted. The Weibull proportional hazard sire model predicted the highest reliabilities for the 16-month criterion, compared to other censorship criteria studied, which can lead to increasing of reproductive and productive efficiency of cows in the herd, since the lower open days of cows and higher number of calves per cow in her productive life.
\end{abstract}

\section{Introduction}

Cow ability to stay in the herd or longevity is an important trait for beef cattle producers. In a commercial herd, the cow becomes profitable only after the rearing and maintenance costs have been paid. However, sometimes cows are discarded before this moment, for health reasons, for example. Therefore, a commercial herd is profitable when the number of cows that remain in production beyond the time after which the costs have been paid for compensate the number of cows that were discarded before that time (Snelling et al., 1995). In Brazil, the few existing studies on beef cattle longevity define this trait as the stayability or probability of surviving up to a specific age given the opportunity to reach that age (Silva et al., 2003, 2006; Van Melis et al., 2007, 2010; Buzanskas et al., 2010).

Caetano et al. (2012) proposed to study cow longevity using the variable age at last calving (ALC), obtained by the difference between the date of the last calving and the date of birth of the cow. This is an easily accessible variable in the Brazilian cattle databases and allows the inclusion of censored observations, which can increase the estimation accuracy of bulls' breeding values for longevity, giving the

\footnotetext{
* Correspondence to: Via de Acesso Prof Paulo Donato Castellane s/n, 14884-900 Jaboticabal, SP, Brazil.

E-mail address: danisio@fcav.unesp.br (D.P. Munari).
} 
support that the breeding value estimation is close to the real. The use of more information as censored observations, can also improve estimates of the genetic parameters, reducing the errors. The difference between the dates of last calving and the last calving of the herd is calculated and used to determine the censor. If this difference is too large, the cow can be discarded. Otherwise, it remains in the herd due to the possibility of future calvings. A censoring criterion should be adopted to determine the threshold that defines whether the cow should be discarded or remain in the herd. The censoring criteria permits using observations of cows that is still alive in the herd and can be used to indicate which management system if more efficient in terms of production and reproduction, since cows which long open days generate higher maintenance costs and decrease in calf production during its productive life.

Caetano et al. (2016) found a heritability estimate of 0.25 for the cow's age at last caving in Nellore beef cattle using as censorship criteria 36 months. This value differs from the values found in the literature for studies that use other variables to measure cow longevity. Silva et al. (2003) found heritability estimates of $0.117,0.122$ and 0.171 for cow longevity up to five, six and seven years old, respectively, using a threshold model. Van Melis et al. (2010) estimated longevity heritability equal to 0.1 , in Nellore cows. For Chianina beef cattle, Forabosco et al. (2006) estimated heritability 0.112 , for productive life. These reports suggest that longevity seems to have low heritability for different populations measured in different ways and estimated by different statistical models. In addition, the late records for longevity and its non-linear behavior make it difficult to select for cow longevity, necessitating an appropriate methodology, such as survival analysis. Thus, due to the economic impact that longevity has in productivity, more studies about this trait need to be developed.

One way to increase the productive and reproductive efficiency of Nelore cows is to identify a censorship criterion. This study aimed to estimate heritability and genetic values for ALC considering three censorship criteria, 16, 26 and 36 months, and if the criteria chosen can change the accuracy of bulls in Nellore beef cattle.

\section{Material and methods}

\subsection{Data source}

The database used in this study was provided by the Nellore Breeding Program, coordinated by the National Association of Breeders and Researchers (Associação Nacional de Criadores e Pesquisadores, ANCP). The production and reproductive records of 22,312 observations of cows distributed in 13 herds located in four different regions (Goiás, Minas Gerais, Mato Grosso do Sul, and São Paulo) in Brazil were used. The animals were born between March 5, 1967 and October 1, 2009. Animal records without birth and calving date were discarded. Weaning occurred between six and eight months old. Cows were the daughters of 2113 bulls. The reproductive management consisted of mating season lasting between 90 and 130 days using artificial insemination or controlled mating.

\subsection{Survival analysis}

The cow longevity was measured using the variable cow's age at last calving (ALC) that is, the difference between the date of the last calving and the date of birth of the cow. The average ALC was 103.95 \pm 39.76 months, with a minimum and maximum of 33 and 259 months old, respectively, and coefficient of variation equal to $38.25 \%$. As some animals had not yet reached their last calving when the data were collected, a censorship criterion was used. This criterion was the difference between the dates of the cow last calving and the last calving in the herd. If this difference is greater than the adopted criterion, the cow either failed or had complete information (uncensored $=1$ ). Otherwise, the cow was either censored or had incomplete information (censored
$=0$ ), indicating the possibility of a future calving. Three censorship criteria adopted were 16, 26 and 36 months. The 16-month criterion was proposed because it is the estimated average interval between births in Nellore. Considering a breeding season of 5 months, the cow that exceeded 16 months without new calving, suggest that this cow entered in breeding season in open days and failed. Thus, the 16-month criterion tries to achieve the ideal situation for livestock production. The 26-month criterion was proposed because it is the average value between 16 and 36 months. Besides that, the 26-month criterion considers that the cow can fail in one breeding season, which generally occurs in commercial farms, but it has a new chance to achieve a new calving. Lastly, the 36-month criterion was considered a long enough time interval for a new calving. Considering, that interval calving ideal is 12 months, the 36-month criterion provide three times chance to cow have a new calving.

The explanatory variables considered were herd, birth year and season, and age at first calving. The effects of the variables were tested using the likelihood ratio test, which compared the likelihood of the full and scale models that excluded the studied variable response. The value of the test (D) is compared with the values of a $X^{2}$ distribution, with the same number of degrees of freedom as in the difference in the number of parameters between the alternative and null models (Dobson, 1990). This procedure was performed for all the variables that had a significant effect $(\mathrm{P}<0.05)$ on ALC. Thus, the contemporary group, composed by herd, birth year and season, was considered as random effect because it had a large number of classes and the heritability estimation formula considered the variance of random effect of contemporary group. Age at first calving was considered as independent fixed effect.

Caetano et al. (2016) studied the dispersion of ALC data and found that they follow the Weibull distribution. In this study, we considered a Weibull proportional hazard sire model for estimating bulls' breeding values and heritability:

$\lambda(t)=\lambda_{0}(t) \exp \{A F C+C G+s\}$

where $\lambda(t)$ is the hazard function at time $\mathrm{t}$ for the cow and depends on cow age at last calving $(\mathrm{t})$ expressed as days. And, $\lambda_{0}(t)$ is the baseline hazard function, which in a Weibull distribution is expressed as:

$\lambda_{0}(t)=\lambda \rho(\lambda t)^{\rho-1}$

where $\lambda$ is the scale parameter and $\rho$ is the shape distribution parameter. This function describes the risk of culling when values of the explanatory variable coefficients are zero.

The terms $A F C, C G$ and $S$ are the effects of age at first calving, contemporary group and sire, respectively. The fixed effect $A F C$ was assumed as being time-independent, that is, the values do not change over time. The random effect $C G$ was assumed as having log-gamma distribution with both shape and scale parameters equal to $\gamma$ in order to force its mean to be 1 (Jenko et al., 2013). The random additive genetic effect of sire $(s)$ assumes a multivariate normal distribution. The gamma parameter of the herd-year effect distribution was estimated jointly with the other effects, after exact algebraic integration of the loggamma herd-year random effect (Ducrocq and Casella, 1996). The sire variance was estimate as the mode of its approximate marginal posterior density obtained after Laplacian integration of the other parameters (Ducrocq and Casella, 1996).

Heritability $\left(h^{2}\right)$ was given by the equation proposed by Ducrocq and Casella (1996):

$h^{2}=\frac{4 \sigma_{s}^{2}}{\sigma_{s}^{2}+\psi^{(1)}(\gamma)+\frac{\pi^{2}}{6}}$

where $\sigma_{s}^{2}$ is the variance between sires, $\gamma$ is the log-gamma distribution of the random effect of contemporary groups, $\psi^{(1)}(\gamma)$ is the trigamma function of $\gamma$ which is equal to the variance of random effects of the contemporary groups, and $\pi^{2} / 6$ is the residual variance. In this study, both log-gamma distribution parameters are equal to $\gamma$ to force the 
average value to be 1 . The trigamma function for $\gamma$ value returns the variance of the random effects of the contemporary groups.

The reliability predicted by the Weibull proportional hazard sire model for the breeding value of each sire, $R$, was also calculated using the formula proposed by Yazdi et al. (2002):

$R=n /\left(n+\frac{1}{\sigma_{s}^{2}}\right)$

where $n$ is the number of uncensored daughters, and $\sigma_{s}^{2}$ is the variance between sires.

Spearman correlation coefficients were used to evaluate the similarity (or gap) between sire classifications based on breeding values for the different censorship criteria. The sire classification based on the predicted breeding values took into account only sires with 25 or more daughters. The top $1 \%$ bulls were chosen based on their genetic merit, resulting in a total of 50 animals. This value was chosen because it is commonly found in the literature in works using censored data. All analyses were performed using the statistical software, Survival Kit version 6.0 (Mészáros et al., 2013).

\section{Results and discussion}

Table 1 shows the total number of observations, the number and percentage of censored and complete observations, and the average ALC for censored and complete observations. The proportion of censored cows ranged from $26.66 \%$ to $38.77 \%$ for the 16 and the 36 -month criteria, respectively. Consequently, the proportion of cows that failed, i.e., were complete, was higher for 16 months and lower for 36 months. This result is expected because the 36-month censoring criterion has a higher number of censored cows, indicating possible future calving, compared with the 16-month criteria. The average ALC for censored observations ranged from 82.67 to 83.60 months for the 26 and the 36month censorship criteria, respectively, and between 85.89 and 86.40 months for complete observations for the 16 and the 26-month, respectively.

Table 2 shows the Weibull distribution estimates for the parameters shape $(\rho)$, gamma distribution $(\gamma)$, trigamma function $\left(\psi^{(1)}(\gamma)\right)$, variance of sire $\left(\sigma_{s}^{2}\right)$ and heritability $\left(h^{2}\right)$. The shape parameter describes the decrease $(\rho<1)$ or increase $(\rho>1)$ of the shape of the base risk function. The failure risk rate decreased over time for $\rho$ values lower than one. For $\rho$ equal to one, the failure risk rate remained constant over time, and the risk function distribution became exponential. Lastly, the failure risk rate increased over time for $\rho$ values greater than one. In this study, the estimates of Weibull distribution shape parameter varied between 3.1241 ( 36 months) to 3.2466 (16 months). Therefore, the risk of culling increased as the ALC increased for all evaluated criteria. These values agree with the estimates reported in the literature. Caetano et al. (2016) estimated $\rho$ equal to 2.45 for the 36 -month criterion for a dataset smaller than the one used in this study. Forabosco et al. (2006) estimated $\rho$ equal to 1.98 in a study that measured longevity of Chianina cows using the variable duration of productive life.

Table 1

Descriptive statistics of cow records for the three censorship criteria evaluated.

\begin{tabular}{|c|c|c|c|}
\hline \multirow[t]{2}{*}{ Item } & \multicolumn{3}{|c|}{ Censorship criteria (months) } \\
\hline & 16 & 26 & 36 \\
\hline Total observations & 21,996 & 21,996 & 21,996 \\
\hline Censored observations (\%) & $5864(26.66)$ & 7198 (32.72) & $8527(38.77)$ \\
\hline $\begin{array}{l}\text { Average ALC for censored } \\
\text { observations (months) }\end{array}$ & 83.22 & 82.67 & 83.60 \\
\hline Complete observations (\%) & $\begin{array}{l}16,132 \\
(73.34)\end{array}$ & $\begin{array}{l}14,798 \\
(67.28)\end{array}$ & $\begin{array}{l}13,469 \\
(61.23)\end{array}$ \\
\hline $\begin{array}{l}\text { Average ALC for complete } \\
\text { observations (months) }\end{array}$ & 85.89 & 86.40 & 86.19 \\
\hline
\end{tabular}

Table 2

Estimates of parameters for the three censorship criteria evaluated.

\begin{tabular}{llll}
\hline Parameters & \multicolumn{2}{l}{ Censorship criterion (months) } \\
\cline { 2 - 4 } & 16 & 26 & 36 \\
\hline$\rho$ & 3.2466 & 3.1772 & 3.1241 \\
$\gamma$ & 0.8329 & 0.8155 & 0.7011 \\
$\psi^{(1)}(\gamma)$ & 2.1616 & 2.2326 & 2.8270 \\
$\sigma_{s}^{2}$ & 0.0996 & 0.0996 & 0.0996 \\
$h^{2}$ & 0.1020 & 0.1002 & 0.0871 \\
\hline
\end{tabular}

$\rho=$ Weibull distribution parameter; $\gamma=$ log-gamma distribution parameter of the random effect of contemporary group; $\psi^{(1)}(\gamma)=$ trigamma function evaluated for $\gamma ; \sigma_{s}^{2}=$ genetic variance of the sire; $h^{2}=$ heritability.

The $\gamma$ value ranges from 0.7011 (36 months) to 0.8329 (16 months). Consequently, the variance estimates of the random effects of contemporary group, obtained by trigamma function of the $\gamma$ parameter ranged from 2.1616 (16 months) to 2.8270 (36 months). One possible explanation for the differences between these estimates is that the likelihood function takes into account whether the observation regards a censored (possibility of future calving or uncensored (culling) animal. As the number of censored animals was different for each criterion, the estimated variance of the contemporary group for each test was also different. Forabosco et al. (2006) estimated the $\gamma$ parameter for the random effects, herd and year of birth, equal to 1.94 with 0.67 variance. Estimates of variance between bulls were equal to 0.0996 for the three censorship criteria. The identical value for all three censorship criteria suggests that the criterion value, and consequently, the number of censored animals, those that can still calve, do not interfere with the variance among bulls. The analyses conducted to evaluate the differences between the three censorship criteria always used the same statistical model, with the same response and explanatory variables. The used database was also the same, as it was the additive relationship matrix used to estimate the genetic variance among bulls. Thus, the only difference between the three analyses is the censorship criteria. These, as stated earlier, are accounted for in the likelihood function estimates, but for this database and the censorship criteria, the genetic variance estimates between bulls was not influenced by this information.

Heritability estimates for the three censorship criteria ranged from 0.0871 ( 36 months) to 0.1020 (16 months). The difference between these estimates is due to the formula used to calculate the heritability, where the denominator takes into account the variance of the random effect of contemporary group. In addition, the highest $\mathrm{h}^{2}$ observed when considered the 16-month criterion, may be due to the presence of fewer censored observations in comparison to the other criteria studied. As the variance estimated for this effect was the highest for 36 months, the heritability became the lowest. The results of this study differ from those found by Caetano et al. (2016) that estimated heritability 0.25 for the 36-month criterion. However, the author considered the contemporary group effect as fixed and the formula used to calculate heritability takes into account only the genetic variance among bulls. Other studies showed similar results to those found in this study. Forabosco et al. (2006) estimated heritability equal to 0.112 also using a heritability formula that takes into account only the bull genetic variance but considering the contemporary group effect as random. Buzanskas et al. (2010) estimated heritability equal to 0.03 for Canchim longevity using the threshold model considering as "success" for cows that have attained at least three calving times at 76 months of age. Van Melis et al. (2010) estimated heritability 0.1 to Nellore beef cattle also using the threshold model studying the number of calvings per female. Silva et al. (2003) used the threshold model to estimate heritability values equal to $0.117,0.122$ and 0.171 for cow longevity at five, six and seven years old, respectively. These reports suggest that longevity have 
low heritability even using different ways to calculate. Besides the longevity is difficult to measure, because it is necessary wait until the cows dead or is discarded. So the use of censoring criterion is a practical and easy way to obtain the data without need to wait until death of the cow, being an interesting way to study the longevity, when the farmer do not have the date of death or cow discard.

The Spearman correlation coefficients estimated for the criteria of 16 and 26,16 and 36 , and 26 and 36 months were equal to -0.2124 , 0.1348 and 0.1211 , respectively $(\mathrm{P}>0.05)$. From these results, it is suggested that the sires' classification depend on the criteria adopted. The differences between the estimates can be explained by the fact that the accuracy of the selected bulls varies depending on the criteria adopted. The formula used to calculate the accuracy of the bulls takes into account the number of daughters with complete information or discarded, and this number varies depending on the censorship criterion adopted. Thus, the a Weibull proportional hazard model predicted reliabilities for each sire and the highest was obtained for the 16month criterion, which is the group with the greatest number of animals with complete data, i.e., those that can be discarded.

\section{Conclusions}

Heritability values obtained were relatively low, but slightly higher from the values reported in the literature to longevity. The results suggest that the use of different censorship criteria can change the prediction accuracy of the breeding values for cow longevity of Nellore cows. The Weibull proportional hazard sire model predicted the highest reliabilities of breeding values of ALC, considering the 16-month criterion, due to the greater number of censored data, which resulted in higher $\mathrm{h}^{2}$, and consequently may generate greater genetic gain for longevity. Thus, 16 months is recommended as a censorship criterion.

\section{Acknowledgements}

We thank the National Association of Breeders and Researchers (ANCP) for providing the data set used in this study. S. B. Ramos received doctoral and pos-doctoral fellowship from Brazilian Federal Coordination of Higher Education (Coordenação de Aperfeiçoamento de Pessoal de Nível Superior - CAPES). S. L. Caetano, R. P. Savegnago, P. A. Bernardes received scholarship from the São Paulo Research Foundation (Fundação de Amparo à Pesquisa do Estado de São Paulo FAPESP - process numbers 2010/05903-0, 2013/20091-0, and 2015/ 25096-6, respectively). D. P. Munari held productivity research fellowship from CNPq (fellowship number 306336/2011-1).

\section{Conflict of interest statement}

The authors Salvador Boccaletti Ramos, Sabrina Luzia Caetano, Rodrigo Pelicioni Savegnago, Priscila Arrigucci Bernardes, Raysildo Barbosa Lôbo e Danísio Prado Munari declare that we don't have any potential conflict of interest including any financial, personal or other relationships with other people or organizations within three years of beginning the work submitted that could inappropriately influence the present work.

\section{References}

Buzanskas, M.E., Grossi, D.A., Baldi, F., Barrozo, D., Silva, L.O.C., Torres Júnior, R.A.A., Munari, D.P., Alencar, M.M., 2010. Genetic associations between stayability and reproductive and growth traits in Canchim beef cattle. Livest. Sci. 132, 107-112.

Caetano, S.L., Rosa, G.J.M., Savegnago, R.P., Ramos, S.B., Bezerra, L.A.F., Lôbo, R.B., Paz, C.C.P., Munari, D.P., 2012. Characterization of the variable cow's age at last calving as a measurement of longevity by using Kaplan-Meier estimator and the Cox model. Animal 7, 540-546.

Caetano, S.L., Rosa, G.J.M., Savegnago, R.P., Ramos, S.B., Bernardes, P.A., Bezerra, L.A.F., Lôbo, R.B., Paz, C.C.P., Munari, D.P., 2016. Estimation of genetic parameters for longevity considering the cow's age at last calving. J. Appl. Genet (ahead of print).

Dobson, A.J., 1990. An Introduction to Generalized Linear Models. Chapman and Hall, Melbourne, AU.

Ducrocq, V., Casella, G.A., 1996. Bayesian analysis of mixed survival models. Genet. Sel. Evol. 28, 505-529.

Forabosco, F., Bozzi, R., Filippini, F., Boettcher, P., Van Arendonk, J.A.M., Bijma, P., 2006. Linear model vs. survival analysis for genetic evaluation of sires for longevity in Chianina beef cattle. Livest. Sci. 101, 191-198.

Jenko, J., Ducrocq, V., Kovac, M., 2013. Comparison of piecewise Weibull baseline survival models for estimation of true and functional longevity in Brown cattle raised in small herds. Animal 7, 1583-1591.

Mészáros, G., Sölkner, J., Ducrocq, V., 2013. The Survival Kit: Software to analyze survival data including possibly correlated random effects. Comput. Methods Progr. Biomed. 110, 503-510.

Silva II.V., J.A., Eler, J.P., Ferraz, J.B.S., Golden, B.L., Oliveira, H.N., 2003. Heritability estimate for stayability in Nelore cows. Livest. Prod. Sci. 79, 97-101.

Silva II.V., J.A., Formigoni, I.B., Eler, J.P., Ferraz, J.B.S., 2006. Genetic relationship among stayability, scrotal circumference and post-weaning weight in nelore cattle. Livest. Prod. Sci. 99, 51-59.

Snelling, W.M., Golden, B.L., Bourdon, R.M., 1995. Within-herd genetic analyses of stayability of beef females. J. Anim. Sci. 73, 993-1001.

Van Melis, M.H., Eler, J.P., Oliveira, H.N., Rosa, G.J.M., Silva II.V., J.A., Ferraz, J.B.S., Pereira, E., 2007. Study of stayabilitity in Nellore cows using a threshold model. J. Anim. Sci. 85, 1780-1786.

Van Melis, M.H., Oliveira, H.N., Eler, J.P., Ferraz, J.B.S., Casellas, J., Varona, L., 2010. Additive genetic relationship of longevity with fertility and production traits in Nellore cattle based on bivariate models. Genet. Mol. Res. 9, 176-187.

Yazdi, M.H., Visscher, P.M., Ducrocq, V., Thompson, R., 2002. Heritability, reliability of genetic evaluations and response to selection in proportional hazard models. J. Dairy Sci. 85, 1563-1577. 